\title{
Kawasaki disease does not affect coronaries alone: large vessels can be involved as well
}

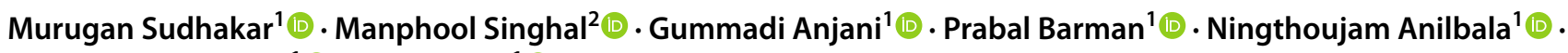 \\ Pandiarajan Vignesh ${ }^{1}$ (1) $\cdot$ Surjit Singh ${ }^{1}$ (1)
}

Received: 22 November 2021 / Revised: 1 February 2022 / Accepted: 26 February 2022 / Published online: 8 March 2022

(c) The Author(s), under exclusive licence to International League of Associations for Rheumatology (ILAR) 2022

\section{Presentation (case narrative)}

A 6-month-old boy was referred with fever for 20 days, conjunctival injection, and maculopapular rash over extremities. He had normal pulses and blood pressure. Hyperemia in the Bacille Calmette-Guérin vaccination site was noted. A clinical possibility of incomplete Kawasaki disease (KD) was considered. Investigations revealed leucocytosis $\left(20.1 \times 10^{9} / \mathrm{L}, N\right.$ : $4-11 \times 10^{9} / \mathrm{L}$; neutrophils $\left.69 \%\right)$; thrombocytosis $\left(612 \times 10^{9} / \mathrm{L}, \mathrm{N}: 150-400 \times 10^{9} / \mathrm{L}\right)$; and raised C-reactive protein (CRP: $87 \mathrm{mg} / \mathrm{L}, N$ : $<6$ ). Two-dimensional echocardiography showed aneurysms involving the right coronary (RCA: $9.4 \mathrm{~mm} ;+24 \mathrm{Z}$ ), the left anterior descending (LAD: $6.4 \mathrm{~mm} ;+16.8 \mathrm{Z}$ ); the left circumflex (LCx: $3.2 \mathrm{~mm}$; $6.4 \mathrm{Z}$ ), and the left main coronary arteries (LMCA: $3.1 \mathrm{~mm} ;+4.6 \mathrm{Z}$ ). Computed tomography angiography (CTA) (Fig. 1) revealed aneurysms involving all four coronaries [largest: LAD (A); and RCA (B)]; abdominal aorta (arrow in C) extending up to internal iliac (asterixis in C); right (D), and left subclavian (E). He was administered intravenous immunoglobulin $(2 \mathrm{~g} / \mathrm{kg})$ and infliximab $(10 \mathrm{mg} /$ $\mathrm{kg}$ ), oral cyclosporine $(5 \mathrm{mg} / \mathrm{kg} / \mathrm{d})$, methylprednisolone (30 $\mathrm{mg} / \mathrm{kg} / \mathrm{d} \times 3$ days) followed by tapering doses of oral prednisolone. Low molecular weight heparin $(2 \mathrm{mg} / \mathrm{kg} / \mathrm{d})$, atorvastatin $(5 \mathrm{mg} / \mathrm{d})$, and aspirin $(3 \mathrm{mg} / \mathrm{kg} / \mathrm{d})$ were also commenced. General well-being improved and inflammatory parameters also came down. However, persistent mild elevation in CRP was noted in the follow-up for which the second dose of infliximab $(10 \mathrm{mg} / \mathrm{kg})$ was administered at the 4th month of illness. At the 8th month of follow-up, the inflammatory markers were normal and the coronary artery aneurysms partially reduced in size (LAD: $5.25 \mathrm{~mm},+12.1$ Z; RCA: $4.3 \mathrm{~mm},+7.9 \mathrm{Z}$ ).

\section{Discussion}

Systemic artery aneurysms (SAAs) had been reported in $0.8-2.2 \%$ of patients with $\mathrm{KD}$, especially in children with a delayed diagnosis who had already developed giant coronary aneurysms $[1,2]$. The involvement of the aorta in SAA was considered very rare and was limited to only case reports [3-5]. Moreover, to the best of our knowledge, the involvement of the ascending aorta had never been reported before in $\mathrm{KD}[2,3]$. SAAs are usually asymptomatic (including the index child), with occasional reports of vascular insufficiency. CTA or magnetic resonance angiography is necessary to delineate the extent of involvement of systemic arteries in KD.

Murugan Sudhakar and Manphool Singhal are joint first authors

Pandiarajan Vignesh

vigimmc@gmail.com

1 Allergy Immunology Unit, Department of Pediatrics, Post

Graduate Institute of Medical Education and Research

(PGIMER), Chandigarh, India

2 Department of Radiodiagnosis, PGIMER, Chandigarh, India 

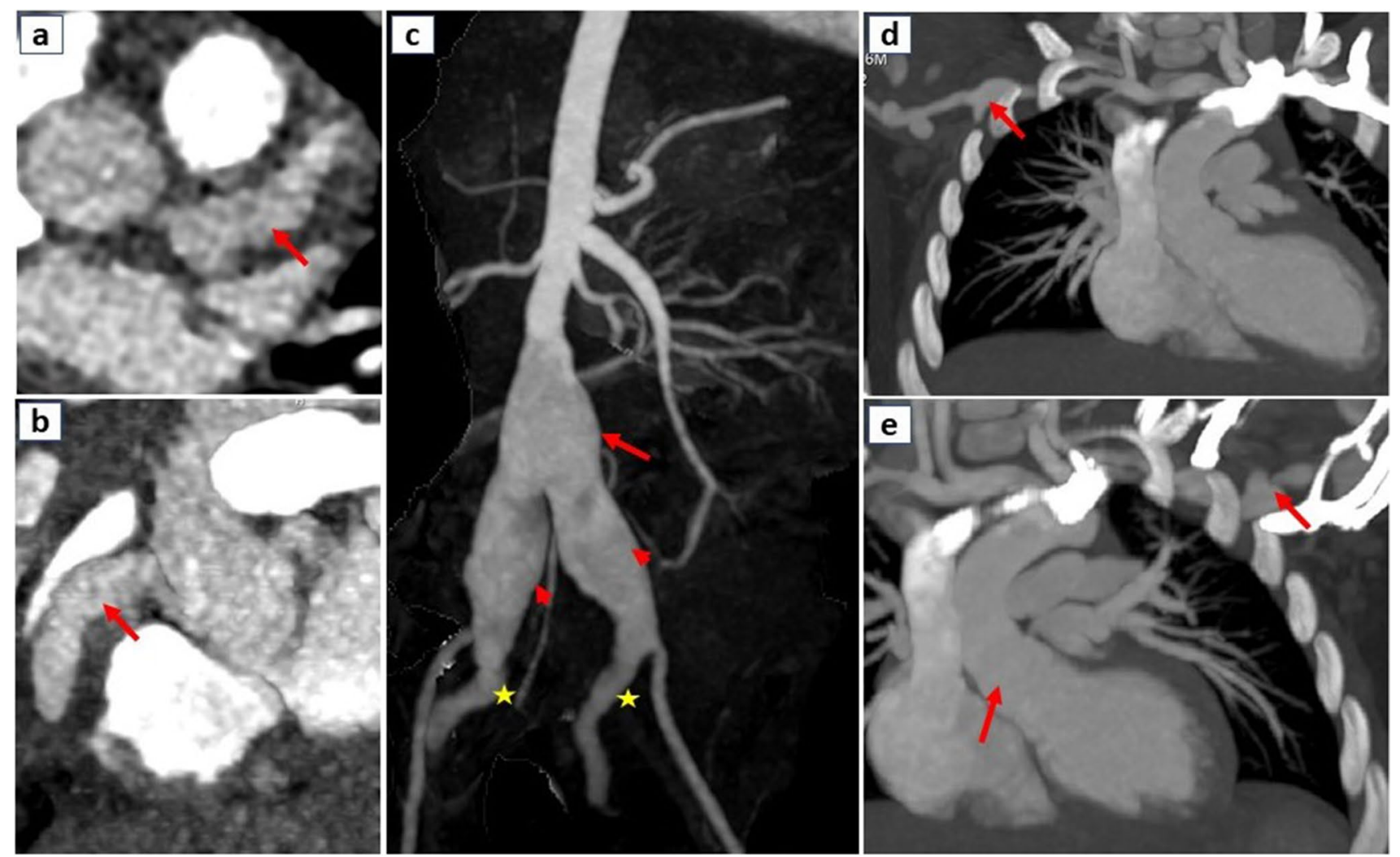

Fig. 1 Computed tomography angiography imaging of index child with Kawasaki disease showing fusiform aneurysm of proximal left anterior descending artery $(6.6 \mathrm{~mm}$ width $\times 16.3 \mathrm{~mm}$ length $)(\mathbf{a})$; fusiform dilatation of the entire right coronary artery (proximal $8 \mathrm{~mm}$, mid $5.2 \mathrm{~mm}$, distal $4.2 \mathrm{~mm}$ ) (b); fusiform dilatation of infrarenal aorta $(17.5 \mathrm{~mm})$ (arrow in c) extending up to common iliac (right $12 \mathrm{~mm}$, left $10.4 \mathrm{~mm}$ ) and internal iliac arteries (right $5 \mathrm{~mm}$, left $3.5 \mathrm{~mm}$ ) (asterixis in c); saccular aneurysm in bilateral distal subclavian arteries (right $5.6 \times 10.3 \mathrm{~mm}$, left $4.8 \times 4.4 \mathrm{~mm})(\mathbf{d}$ and $\mathbf{e})$; and dilated ascending aorta $(12 \mathrm{~mm})(\mathbf{e})$
Author contribution MS and MS: writing of initial draft of the manuscript, editing and revision of manuscript at all stages of its production, and review of the literature. MS and MS are joint first authors. GA, $\mathrm{PB}$, and NA: management and follow-up of the patient and editing of the manuscript. PV and SS: evaluation of the patient, follow-up of the patient, editing, and approval of the manuscript.

\section{Declarations}

Disclosures None.

Consent for publication Consent for publication was taken from parents for both content and image.

\section{References}

1. Zhao QM, Chu C, Wu L, Liang XC, Sun SN, He L, Zhao L, Wang F, Huang GY, Niu C, Liu F (2019) Systemic artery aneurysms and Kawasaki disease. Pediatrics 144(6):e20192254. https://doi.org/ 10.1542/peds.2019-2254
2. Kato H, Sugimura T, Akagi T, Sato N, Hashino K, Maeno Y, Kazue T, Eto G, Yamakawa R (1996) Long-term consequences of Kawasaki disease. A 10- to 21-year follow-up study of 594 patients. Circulation 94(6):1379-85. https://doi.org/10.1161/01. cir.94.6.1379

3. Petrunić M, Drinković N, Stern-Padovan R, Mestrović T, Lovrić D (2009) Thoracoabdominal and coronary arterial aneurysms in a young man with a history of Kawasaki disease. J Vasc Surg 50(5):1173-1176. https://doi.org/10.1016/j.jvs.2009.05.025

4. Hoshino S, Tsuda E, Yamada O (2015) Characteristics and fate of systemic artery aneurysm after Kawasaki disease. J Pediatr 167(1):108-12. e1-2. https://doi.org/10.1016/j.jpeds.2015.04.036

5. Briceno-Medina M, Perez M, Waller BR, Sathanandam S (2016) Systemic and pulmonary artery aneurysms in incomplete Kawasaki disease. J Cardiol Cases 13(6):185-188. https://doi.org/10. 1016/j.jccase.2016.02.003

Publisher's note Springer Nature remains neutral with regard to jurisdictional claims in published maps and institutional affiliations. 